\title{
A Study on Copycat Suicides and Werther Effect: Myth or Reality
}

\author{
Tushar Saini ${ }^{1}$, Vijay Arora ${ }^{2}$, Susheel Sharma ${ }^{3}$, Deepak Kumar ${ }^{1}$, Vipul Parmar $^{1}$, Saurbh Sharma ${ }^{1}$ \\ ${ }^{1} \mathrm{PG}$ Resident, ${ }^{2}$ Professor and Head, ${ }^{3}$ Associate Professor \\ ${ }^{1-3}$ Department of Forensic Medicine and Toxicology, Dr. Rajendra Prasad Government Medical College, Kangra at Tanda, Himachal \\ Pradesh
}

\begin{abstract}
Suicide is a critical mental health problem, and during this COVID-19 pandemic, various mental health problems have arisen, leading to an increased tendency for suicides. It is difficult to believe if we lose someone due to suicide, especially if he/she is a popular figure in society, as it does not affect the family and friends of that person but also brings a sense of loss to the community. Copycat suicide is defined as duplication or copycat of another suicide that the person attempting suicide knows about either from the local knowledge or on account of depicting the original suicide on television and in other media. ${ }^{1}$ Werther effect defines as a popular term for an increase in suicide rates that follow media coverage of suicides or are inspired by reading about others suicides or are linked to a friend or family member who committed suicide. ${ }^{2}$

In June 2020, a renowned Bollywood actor Sushant Singh Rajput was found dead, hanging from the ceiling fan at his house in Bandra, Mumbai, and the alleged manner of death was ruled to have been suicide. ${ }^{3}$ For around 3 months, all the media was covering this news.

The aim of this study is to assess the effect of media coverage of this case (i.e., Werther effect) on the increase in the cases of suicides by hanging (i.e., Copycat suicides) in the rural areas of Himachal Pradesh. Out of 249 medico-legal autopsies in 2020 during the period from June 14 to December 31, there were 28 cases of hanging which constitutes $11.24 \%$, and if we compare it with 2018 and 2019, there were a total of 278 and 253 cases during this period, and amongst these cases, only 13 and 15 cases respectively of hanging were reported which constitutes 4.67 and $5.14 \%$. This study shows that there is about 2 times increase in hanging cases after the death of this renowned actor. In June 2020, just after his death, there is a drastic increase in hanging cases, constituting $24 \%$. Male predominance is more than females as males constitute $75 \%$ of cases, which is more than the females, which constitute only $25 \%$ of cases. The age group of 21-30 years shows more predominance as compared to the other age groups.
\end{abstract}

Keywords: Copycat Suicide, Hanging, Suicide, Werther Effect. Int J Eth Trauma Victimology (2021). DOI: 10.18099/ijetv.v7i01.3

\section{INTRODUCTION}

Suicide is a major concern in the Indian population. More than one lakh (one hundred thousand) lives are lost every year to suicides in our country. Suicide is a critical mental health problem and during this COVID-19 pandemic, various mental health problems have arisen leading to an increased tendency for suicides. The study titled "Analysis of news media reports of suicides and attempted suicides during the COVID-19 lockdown in India" said that there were 369 cases of suicides and attempted suicides during the COVID-19 lockdown compared to 220 reported suicides in the corresponding dates in 2019. ${ }^{4}$ Mental disorders occupy a leading position in the milieu of causation of suicide. The majority of studies note that around $90 \%$ of those who die by suicide have a mental disorder. ${ }^{5}$ Suicides reporting by the media is a common cause for the increase in the number of suicides. In our study, there is a drastic increase in the number of hanging cases after the news of the death of a renowned actor. Especially, exposure to media reports of a celebrity's death put forth a copycat effect on at-risk individuals. ${ }^{6}$

Copycat suicide is defined as duplication or copycat of another suicide that the person attempting suicide knows

CIJETV. All rights reserved
Corresponding Author: Dr. Vijay Arora, Professor and Head,Department of Forensic Medicine and Toxicology, Dr. Rajendra Prasad Government Medical College, Kangra at Tanda, Himachal Pradesh, e-mail: drvjarora@gmail.com

How to cite this article: Saini T, Arora V, Sharma S, Kumar D, Parmar V, Sharma S. A Study on Copycat Suicides and Werther Effect: Myth or Reality. Int J Eth Trauma Victimology. 2021;7(1): 11-13.

Source of support: Nil

Conflict of interest: None

Received:20/05/2021;

Accepted:08/06/2021;

Received in revised form: 01/06/2021; Published:25/06/2021

about either from the local knowledge or on account of the depiction of the original suicide on television and in other media.

Werther effect defines as a popular term for an increase in suicide rates that follow media coverage of suicides or are inspired by reading about others suicide are linked to a friend or family member who committed suicide.

In social sciences and in medicine, the term "Werthereffect" is used as a synonym for media-induced imitation effects 
of suicidal behavior. One of the earliest known associations between the media and suicide arose from Goethe's novel Die Leiden des Jungen Werthers (The Sorrows of Young Werther). After its publication in 1774, young men began to mimic the main character by dressing in yellow pants and blue jackets. In the novel, Werther shoots himself with a pistol after being rejected by the woman he loves. Shortly after its publication, there were reports of young men using the same method to kill

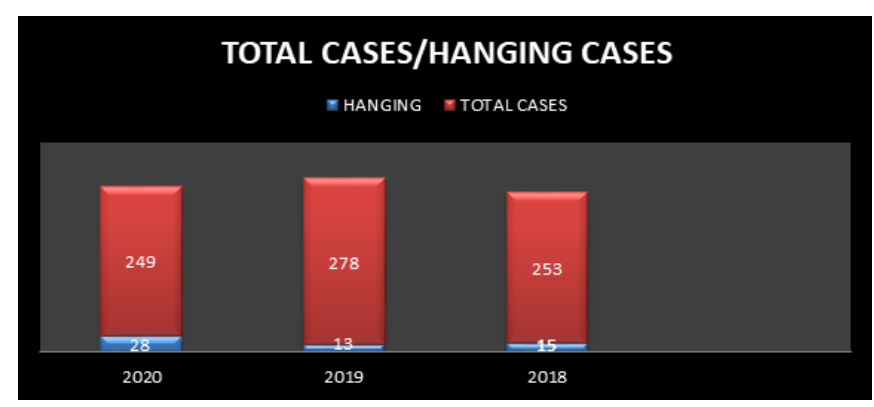

Figure 1: Graph showing comparison of total number of autopsies and cases of Hanging in 2020, 2019 and 2018

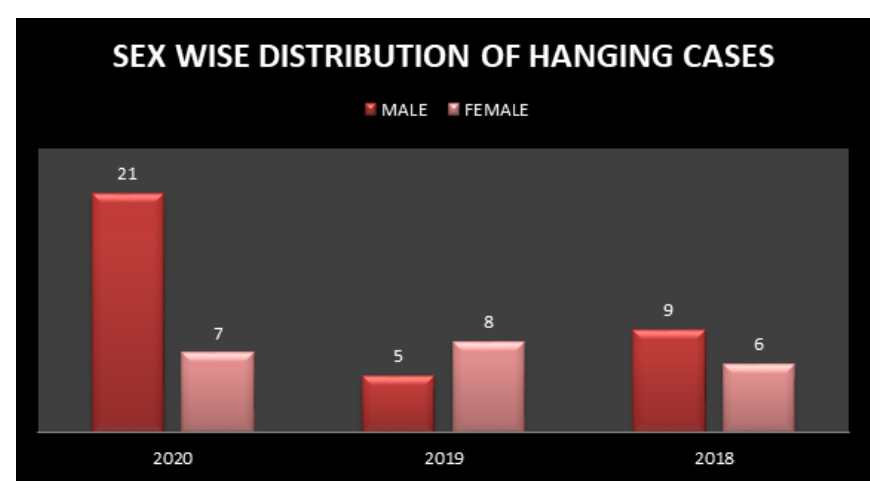

Figure 2: Graph showing Sex Wise Distribution of Hanging Cases in 2020 vs. 2019 and 2018

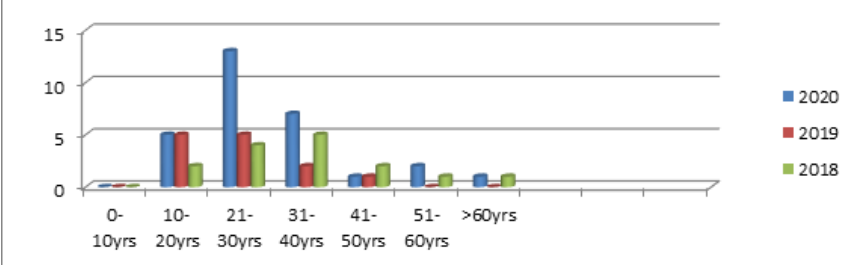

Figure 3: Age-wise distribution of hanging cases in 2020 vs 2019 and 2018

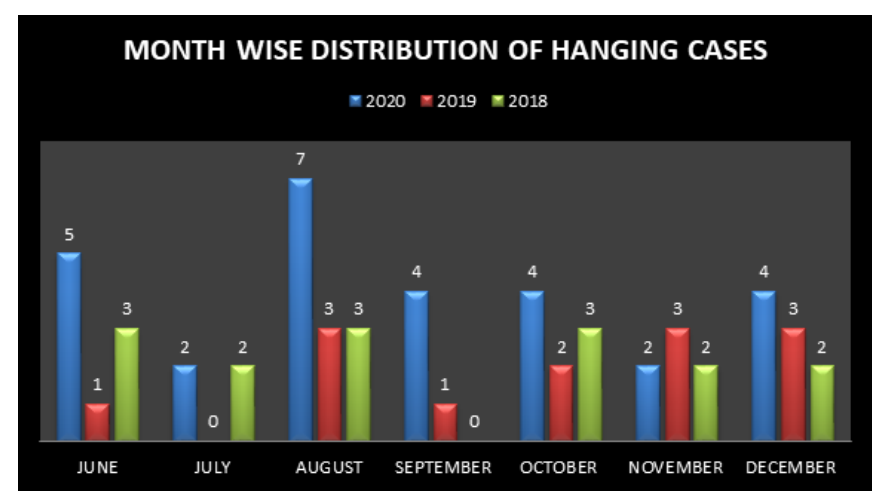

Figure 4: Monthwise distribution of cases of hanging themselves in acts of hopelessness. ${ }^{7}$ The "Werther-effect" term was coined by researcher David Phillips in $1974 .^{8}$

\section{Materials and Methods}

This study comprises all the Medico-Legal cases brought for the autopsy to the mortuary of Dr Rajendra Prasad Govt. Medical College, Kangra, situated at Tanda, from June 14 to December 31, 2020. Medical history and the history of the incident were obtained through hospital records and police information that accompanied the dead body and through brief interviews with the relatives of the deceased. The data obtained was computed, and descriptive analysis of baseline characteristics was analyzed and summarized with the data of the previous two consecutive years.

\section{Results}

In total, 249 cases were brought to the mortuary from June 14 to December 31, 2020; out of which 28 cases were of hanging ( 21 were of males and 7 were of females), constituting $11.2 \%$ of cases as compared to 13 cases of hanging out of 278 cases constituting $4.67 \%$ and 15 cases out of 253 cases constituting 5.9\% in the years 2019 and 2018 respectively. (Figure 1)

In 2020 there were 28 cases of hanging; 21 male i.e., $75 \%$ as compared to 7 females, i.e., $25 \%$. Whereas in 2019 , there were 5 males, i.e., $38.4 \%$, and 8 females, i.e., $61.5 \%$. Similarly, in 2018 , there were 9 males, i.e., $60 \%$, and 6 females, i.e., $40 \%$. (Figure 2)

In the present study, 13 (46.5\%) out of 28 cases were in the age group of 21-30 years, while in the previous years, 2019 and 2018 , the cases in this age group were 5 cases (38.4\%) and 4 cases (26.6\%) respectively (Figure 3 ).

The study also shows that out of 21 cases, 5 cases $(23.8 \%)$ of hanging were reported from $14^{\text {th }}$ to June 30,2020 (16 days), i.e., immediately after this incidence (Figure 4).

\section{Discussion}

In this study, there is an increase in the deaths due to hanging by about $6.5 \%$ and $5.3 \%$ as compared to two previous consecutive years, i.e., 2019 and 2018, respectively, which may be attributed to the Werther effect leading to copycat suicides.

Our study also shows that the age group of 21-30 years is more vulnerable to copycat suicides by hanging, constituting $46.4 \%$ of cases. Copycat suicide was the leading cause of death in those aged 21-30 years and the second leading cause of death in the age group of $31-40$ years.

Males constitute $75 \%$ of cases which is more than the females constituting $25 \%$ of cases. To investigate whether there was a relationship between the sex of the celebrity and the sex of the person who committed copycat suicide, the data showed that males who died due to hanging were more as compared to females.

In this study, we have seen a drastic increase in the cases of hanging in June 2020 after the death of a renowned actor who was given excessive coverage in media. 


\section{Conclusion}

Social learning theory is a theory of learning process and social behavior which proposes that new behaviors can be acquired by observing and imitating others. As anticipation from this theory, if there is a greater coverage of suicides in the mass media, the copycat suicides also increase. ${ }^{9}$

Differential identification theory gives strong support for the increase in copycat suicides after the death of a renowned actor. It states that a person pursues criminal behavior to the extent that he identifies himself with real or imaginary persons from whose perspective his criminal behavior seems acceptable. $^{10}$

Certain age groups, mainly $21-40$ yrs age group, may respond more to the publicized suicide stories than their other age group counterparts. Individuals who commit suicide after a celebrity suicide are likely to be younger and prefer hanging as a method of suicide, which are more strongly associated with higher effect sizes of celebrity suicide. ${ }^{11}$ Prerequisite of mental health service and increase of mental health care accessibility may help to prevent suicide and suicidal behaviors for vulnerable populations.

Werther's effect on copycat suicides was also explained earlier. From 1983 to 1986, there was a sharp increase in the number of suicides in Vienna, directly linked to a dramatic increase in their coverage in the media. In 1987 Australian Suicide Prevention launched a media campaign to change in the nature of press coverage of the suicides. As a result, after 1987, there was a drastic decrease in the number of suicides. ${ }^{12}$ Therefore, there must be some guidelines and nature of press coverage on suicide cases of celebrities so that the direct relation between Copycat suicides and the Werther effect can be broken. So, at last, the Werther effect and copycat suicide are a reality or a myth, and our study shows that both are directly related to each other, and it is a reality, not a myth. And our media should change its quality and quantity of reporting so that suicides of vulnerable groups can be reduced as our society is easily attracted to the media world.

\section{BibLIOGRAPHY}

1. Susan K.W, Richard H. Abnormal Psychology. 7th ed. New Delhi: Mc Graw Hill; 2015.p.62.

2. Segen JC. Dictionary of Modern Medicine $.1^{\text {st }}$ ed. New York : Mc Graw Hill. 2012.

3. The Week, Entertainment section. HYPERLINK "https://www. theweek.in/news/entertainment/2020/06/24/sushant-singhrajputs-final-autopsy-report-confirms-suicide-rules-out-foulplay.html"'Sushant Singh Rajput's final autopsy report confirms suicide; rules out foul play"; $24^{\text {th }}$ June 2020.

4. The Wire, Health Section. 67\% Increase in Reports of Suicidal Behaviour during Lockdown: Study; $9^{\text {th }}$ December 2020.

5. Laxmi V, Sujit J, Jane P, Harvey W. Suicide in developing countries (2): Risk factors. Crisis. 2005;26(3):112-119.

6. Steven S. Celebrities and suicide: A taxonomy and analysis, 1948-1983. American Sociological Review. 1987 Feb; 52(3): 401-412.

7. David G.M.Social Psychology.10 ${ }^{\text {th }}$ ed. New York: McGraw Hill. 2009

8. De Wyze, Jeannette (2005-03-31). HYPERLINK "http://www. sandiegoreader.com/news/2005/mar/31/why-do-they-die/"'Why Do They Die?"; San Diego Reader; Retrieved 2021-03-05.

9. Albert B. Hyperlink "https://web.archive.org/web/20131024214846/ http:/www.jku.at/org/content/e54521/e54528/e54529/e178059/ Bandura_SocialLearningTheory_ger.pdf""Social Learning Theory" (PDF). General Learning Corporation. Archived from HYPERLINK "http://www.jku.at/org/content/e54521/e54528/ e54529/e178059/Bandura_SocialLearningTheory_ger.pdf"the original (PDF) on 24 October 2013.

10. Victor M. Matthews.Differential Identification: An Empirical Note. Social Problems. $1^{\text {st }}$ ed. Canada: Winter publishing house; 1968 "https://www.jstor.org/stable/i232896": pp. 376-383.

11. Myung W, Won H.H., Fava M, Mischoulon D, Yeung A, Lee $\mathrm{D}$ et al. Celebrity Suicides and Their Differential Influence on Suicides in the General Population: A National PopulationBased Study in Korea. HYPERLINK "https://www.ncbi.nlm. nih.gov/pmc/articles/PMC4390591/"Psychiatry Investig. 2015 Apr; 12(2): 204-211.

12. Niederkrotenthaler T, Sonneck G. Assessing the impact of media guidelines for reporting on suicides in Austria: interrupted time series analysis. Australian and New Zealand Journal of Psychiatry. 2007 June; 41(5):419-428. 